INFORMASI: Kajian Ilmu Komunikasi - ISSN (p) o126-0650; ISSN (e) 2502-3837 Vol. 48, No. 1 (2018), pp.15-32. doi: http://dx.doi.org/10.21831/informasi.v48i1.18417

\title{
STRATEGIZING SMALL AND MEDIUM ENTERPRISES DEVELOPMENT THROUGH ICT-RELATED INNOVATIONS ADOPTION: MODERATING INFLUENCE OF GENDER, AGE AND EXPERIENCE
}

\author{
Adamkolo Mohammed Ibrahim \\ adamkoloibrahim@yahoo.com \\ Department of Mass Communication, University of Maiduguri, PMB 1069, Maiduguri, \\ Borno State, Nigeria
}

\begin{abstract}
The rapid advancement in information and communication technology (ICT) has brought huge entrepreneur benefits and challenges. A key challenge that has been less researched is the demand for skilled manpower in relation to the issue of the role employees' age and gender play in driving SMEs' ICT-related innovations adoption. This paper attempted to determine the moderating role of three important workers' demographic characteristics (age, gender and experience) on the use of innovations related to ICT by SMEs. Adopting the unified theory of acceptance and use of technology (UTAUT) perspective, a questionnaire was designed and administered to 400 employees selected from 43 SMEs in the Malaysian state of Selangor. The results of multiple regression analysis indicate that performance expectancy, effort expectancy, social influence and facilitating conditions all have significant impacts on ICT-related technology innovations adoption (ICTRIA) while the moderator analysis confirmed that the two gender categories, different age groups and different experience levels have specific moderating influence on the relationship paths between the four predictors and technology innovations use. Novel findings show that performance expectancy and social influence are more salient for older female and younger female workers to run jobs related to ICT innovations use in the firm respectively.
\end{abstract}

Keywords: Gender, Age and Experience, Enterprise Development, ICT Adoption, Innovations, SME Employees. 


\section{INTRODUCTION}

Small and medium enterprises (SMEs) play a vital part in the provision and sustaining of employment and wealth creation especially in developing countries. In Malaysia, according to statistics from the country's SME Corporation (SMECORP) 2016 report the percentage of the workers employed in SMEs has sharply risen from 56.4 per cent in 2012 to 65.3 per cent in 2016 (SMECORP, 2017a). Hence, authorities and critical stakeholders are providing increased resources as a way of leveraging political and financial underpinning toward the growth and development of SMEs. This is based on the continuous emergence of evidence supporting the notion that the survival and success of SMEs are crucial to the economic buoyancy and stability of any nation (AlRahbi, 2017; Duan, Mullins, Hamblin, Stanek, Sroka, Machado, \& Araujo, 2002).

However, employees' qualities, e.g., demographic characteristics and expertise will be key to the growth of SMEs given that acute shortage of the right category of employees with the right work skills could negatively affect the firm's ability to survive and competitive favourably in market and remain in business. To help SMEs understand the dynamics of manpower in relation to organisational expansion and business growth, adoption of business technology innovations such as e-business or e-commerce and enterprise resource management system is often regarded as the most effective way to achieve those goals (Tan, Chong, Lin, \& Eze, 2010).

Broadly, SMEs are defined as businesses that employ fewer than 250 people and are independent from other organisations. An enterprise is considered an SME based on annual sales turnover or number of full-time employees. In Malaysia, small enterprises are businesses whose sales turnover ranges from RM300,00o to about RM15 million (approximately $\$ 77,000$ to $\$ 3.80$ million) or full-time employees ranging from 5 to 74 , while medium enterprises are businesses with sales turnover ranging from RM15 million to RM5o million (approximately \$3.85 million to $\$ 12.82$ ) or full-time employees ranging from 75 to 200 workers (SMECORP, 2017b). Available records show that SMEs nowadays constitute a major business sector in most countries around the world, covering a wide range of industries. In most countries, the number of SMEs exceeds the number of large firms, and they (SMEs) contribute strongly to the GDP (AlRahbi, 2017).

According to Department of Statistics Malaysia (DOSM) the Malaysia Economic Census 2011 report indicate that SMEs constitute $97.3 \%$ of total business establishments $(645,136)$ in the country and employ over $4,854,142(57.4 \%)$ of the total employments $(8,460,971)$ in 2012 (DOSM, 2014). However, only $27 \%$ of the 645,136 SMEs in the country use advanced ICTrelated innovations such as e-commerce, website and personal computer; however, quite many $(67 \%)$ of them use basic ICTrelated innovations such as Internet, e-mail, telephone and mobile phone (MCMC, 2014). Research has shown that innovations related to ICTs possess great potential to provide ample opportunities for the development of small and medium-sized enterprises (SMEs) and improvement of socio-economic indices of nations (Abd Rahman, Kamarulzaman, \& Sambasivan, 2013).

This paper reports the empirical findings on the relationship between the four UTAUT predictors (PE, EE, SI and FC) and the dependent variable (ICTRIA) focusing on the influence of employee's demographics on SMEs' ICT-related innovations adoption. The study which was performed in the Malaysian state of Selangor first attempts to address the following questions: (i) what is the effect of PE on ICTRIA? (ii) what is the effect of EE on ICTRIA? (iii) what is the effect of SI on ICTRIA? and (iv) what is the effect of FC on ICTRIA? Subsequently, the paper attempted to address the following questions, which are the primary objectives of this study: (v) what is the moderating influence of employees' age on SMEs' ICTrelated innovations adoption? (vi) what is the moderating influence of employees' gender on SMEs' ICT-related innovations adoption? 
and (vii) what is the moderating influence of employees' prior ICT use experience on SMEs' ICT-related innovations adoption? The paper is structured into the following sections, namely literature review, research methodology, structural model analysis, results, discussion of findings and research synthesis and finally, conclusion, which includes implications of the findings and limitations of the study.

\section{LITERATURE REVIEW}

\section{The Theoretical Background of this Study}

The unified theory of acceptance and use of technology (UTAUT) model was developed by Venkatesh, Morris, Davis, \& Davis (2003) by merging prominent ICT adoption research models that have roots in social cognitive theory. With an adjusted variance $\left(\mathrm{R}^{2}\right)$ of $70 \%$, UTAUT model is widely acclaimed the most comprehensive of ICTrelated innovations adoption models because it outperforms all the models merged. UTAUT uses four key determinants of ICTrelated innovations adoption and/or use intention, namely performance expectancy $(\mathrm{PE})$, effort expectancy (EE), social influence (SI) and facilitating conditions (FC). The model also uses four moderators, namely gender, age, experience and voluntariness of use (Venkatesh et al., 2003). However, in this paper the voluntariness dimension was dropped due to the absence of contexts warranting compulsion of technology use or otherwise. Performance Expectancy refers to the degree to which an individual believes that using ICT-related innovations will help him or her to attain gains in job performance. Effort Expectancy refers to the degree of ease/effort associated with the use of ICTrelated innovations by an individual user. Social Influence refers to the degree to which an individual user perceives that important others believe that he or she should use ICTrelated innovations. Facilitating Conditions refers to the degree to which an individual user believes that an organisational \& technical infrastructure exists to support use of ICT-related innovations in the organisation (Taiwo \& Downe, 2013; Venkatesh et al., 2003).

Performance expectancy: The UTAUT model was adopted in a research study conducted by Liao (2013) that examined the adoption of Web 2.o technology among Australian agro-based firms for business development. The research found that performance expectancy, effort expectancy and social influencepredict Web 2.oadoption. Somewhat similar results were obtained when a moderated version of UTAUT was employed by Aoun, Vatanasakdakul and $\mathrm{Li}$ (2010) to investigate the adoption of Accounting Information System (AIS) by accounting professionals in Australia. The results show that performance expectancy, effort expectancy and facilitating conditions positively influence adoption of AIS systems for the development of accounting profession.

Effort expectancy: The innovation diffusion theory (IDT) perspective was adopted by Odoom, Anning-Dorson \& Acheampong (2017) to investigate factors affecting the adoption of social media marketing among Ghanaian SMEs for entrepreneurial development. Using a sample of 210 SMEs that use social media and structural equation modelling (with subgroups analysis), the study discovered that interactivity (a construct related to effort expectancy) significantly predict social media marketing adoption. This finding is quite interesting in that the nature of social media marketing, which relies heavily on retailercustomer interactions online, the question of the degree of interactivity (effort input to use communication cues), which has roots in effort expectancy (Chiu, Chen, \& Chen, 2017) is an important factor determining social media use. A study confirms that employees' training, management support and skills affect adoption (Rusdi, Hassan, Munir, \& Mohamad, 2017).

Social influence: A study involving a sample of 240 SME workers was performed to determine the adoption of enterprise resource planning (ERP) among Peruvian SMEs for business development. The study 
revealed that social influence significantly predicts use behaviour (Maldonado, Khan, Moon, \& Rho, 2011). Factors affecting the adoption of fishing technologies such as global positioning system (GPS) and sonar systems for entrepreneurial development among Malaysian fishermen was performed by Zarehmohzzabieh, Samah, Omar, Bolong \& Shaffril (2014). Social influence was found to moderately predict use. Recently, the adoption of e-commerce for SMEs' growth among Indian women entrepreneurs was investigated and it was found that social influence significantly predict use (Goswami \& Dutta, 2017).

\section{Facilitating conditions: The} adoption of internet banking for business development among SME managers and employees was conducted among small and medium enterprises in China. The findings suggest that performance expectancy and social influence and facilitating conditions predict use behaviour (Cheng, Liu, Qian \& Song, 2008). A study conducted by $\mathrm{He}$ and $\mathrm{Lu}$ (2007) found that performance expectancy, social influence and facilitating conditions are predictors of SMEs' acceptance of mobile e-commerce services and advertising for business development. The study also found that behavioural intention predicts use behaviour.

\section{Influence of Gender, Age and Prior Use Experience on SME Technology Innovations Adoption}

Past research has shown that gender roles have a strong association with psychological phenomena and are relatively long-lasting, although they may be open to change over time. Like gender, age is theorised to play a moderating role in predicting ICT-related innovations adoption. Research on jobrelated attitudes suggests that younger SME employees may place more importance on extrinsic job rewards (Srinivas \& Yasmeen, 2017). Furthermore, existing literature has shown that gender and age differences also exist in SMEs' technology adoption (Maruping, Bala, Venkatesh, \& Brown, 2017;
Qureshi \& Xiong, 2017).

In furtherance of discussion on gender and age effects, it is interesting to note that past research (Mehta, 2016; Morris, Venkatesh \& Ackerman, 2005) suggests that findings of studies on gender differences can be confusing if not linked to age. For example, looking at traditional societal gender roles, the salience of industrial (job-related) factors may change significantly by, say, becoming supplanted by family-related responsibilities for women employees between when they join the SME and when they decide to have children (Venkatesh et al., 2003).

Gender influences may be driven by psychological phenomena enmeshed within socially constructed gender roles (EscobarRodriguez \& Carvajal-Trujillo, 2014). So are performance and effort expectancies (Venkatesh et al., 2003). Cited in Morris and Venkatesh (2000), a meta-analytic review of age effects performed by Rhodes (1983) concluded that affiliation needs increase with individuals' age, which suggests that older employees are more likely to place increased importance on social influences. However, the effect has been discovered to decline with experience.

Existing literature has shown that effort expectancy, whose main concept is the easiness associated with using ICT-related innovations has been found to be more salient for women than for men workers. Moreover, gender differences could be prompted by cognitive factors linked to societal gender roles (Bandura, 2001; Venkatesh \& Morris, 2000) as mentioned earlier. The literature indicates that advanced age is often linked to inability to process complex stimuli easily and give attention to job-related information (Morris \& Venkatesh, 200o). According to research, both actions (ability to process complex stimuli easily and paying attention to job information) may be necessary when using ICT software systems. Furthermore, the notion that constructs related to effort expectancy will be stronger determinants of individuals' technology adoption for women and for older employees has been supported (Morris \& Venkatesh, 200o; Venkatesh et al., 
2003). Many previous studies have supported the notion that gender and age moderate effort expectancy (Al-Gahtani, Hubona, \& Wang, 2007; Verheul, Thurik, \& Grilo, 2008).

Social influence is related to social affiliations. Increase in age brings about increase in reliance needs, suggesting that older employees are more likely to rely on social influences, with the effect waning off with increased experience (Morris \& Venkatesh, 200o). Issues surrounding facilitating conditions (whose main concept focuses on the support infrastructure), are substantially captured within the effort expectancy construct (which focuses on the ease with which the technology tools can be applied. Previous studies have provided support for full mediation of the effect of facilitating conditions on technology adoption by effort expectancy (Venkatesh, Brown, Maruping, \& Bala, 2008; Venkatesh et al., 2003). Facilitating conditions have also been found to have a direct effect on technology adoption more salient than that predicted by behavioural intentions alone (Taylor \& Todd, 1995; Venkatesh \& Morris, 2000).

\section{The Hypotheses of this Study}

As mentioned earlier, three demographic variables, namely gender, age and technology innovations adoption experience were theorised to moderating the effect of four predictors and ICT-related innovations adoption. To test that, four hypotheses were formulated as outlined below. However, prior to running the moderation analysis the relationship between the four key predictors and technology innovations adoption was determined using four hypotheses.

The straight-path relationship hypotheses:

$\mathbf{H}^{\mathbf{H}}$ : Performance expectancy significantly affects ICT-related innovations adoption.

$\mathbf{H}^{2}$ : Effort expectancy significantly affects ICT-related innovations adoption.

$\mathbf{H}^{3}$ : Social influence significantly affects ICTrelated innovations adoption.
$\mathbf{H}^{4}$ : Facilitating conditions significantly affects ICT-related innovations adoption.

The moderation paths hypotheses:

$\mathbf{H}^{5}$ : Gender, age and experience will moderate the relationship between performance expectancy and ICT-related innovations adoption.

$\mathbf{H}^{6}$ : Gender, age and experience will moderate the relationship between effort expectancy and ICT-related innovations adoption.

$\mathbf{H}^{7}$ : Gender, age and experience will moderate the relationship between social influence and ICT-related innovations adoption.

$\mathbf{H}^{8}$ : Gender, age and experience will moderate the relationship between facilitating conditions and ICT-related innovations adoption.

\section{RESEARCH METHODOLOGY}

\section{Sampling Procedure and Research Design}

This study adopted a quantitative approach. The data was collected from some 400 employees of 43 SMEs at the state of Selangor in Malaysia using a survey questionnaire. The employees were selected using purposive sampling approach while the 43 SMEs were selected using simple random sampling, with help of an online random selection software at randmiser.com.

A multi-group analysis approach was used to determine the moderating influence of gender, age and experience on the effect of the predicting constructs on technology innovations adoption. Data for descriptive statistics was obtained from the respondents' demographic information. As mentioned earlier, the study adopted the UTAUT model. Cognitive factors have been identified as very complex phenomena to be investigated (Agarwal \& Prasad, 1999; Taylor \& Todd, 1995); hence the need for concept-inclusive constructs like those of the UTAUT model (see Rahman \& Ramos, 2014).

\section{Respondents of the Study}

Of the 382 SME employees whose data were analysed, 201 (representing 52.6 per 
Table 1: Respondents' Demographic Information

\begin{tabular}{|c|c|c|c|c|}
\hline Variable & $\mathbf{F}$ & $\%$ & Mean & SD \\
\hline Gender & & & 1.40 & .490 \\
\hline Male & 230 & 60.2 & & \\
\hline Female & 152 & 39.8 & & \\
\hline Age Category & & & 31.05 & 8.09 \\
\hline 18 & 8 & 2.1 & & \\
\hline $18-28$ & 149 & 39.0 & & \\
\hline $29-39$ & 170 & 44.5 & & \\
\hline $40-50$ & 38 & 9.9 & & \\
\hline 50 & 17 & 4.5 & & \\
\hline Monthly Income (RM000.00) & & & 2.51 & 0.57 \\
\hline$<3,000$ & 221 & 57.9 & & \\
\hline $3,001-5,000$ & 81 & 21.1 & & \\
\hline $5,001-7,000$ & 71 & 18.6 & & \\
\hline 7,001 & 9 & 2.4 & & \\
\hline Educational Qualification & & & 5.51 & 1.72 \\
\hline No formal schooling & 11 & 2.9 & & \\
\hline UPSR & 21 & 5.5 & & \\
\hline SRP/PMR/LCE & 16 & 4.2 & & \\
\hline SPM/SPMV/MCE & 69 & 18.1 & & \\
\hline Certificate & 16 & 4.2 & & \\
\hline STPM/Diploma & 107 & 28.0 & & \\
\hline Bachelor's & 132 & 34.6 & & \\
\hline Master's & 10 & 2.6 & & \\
\hline Number of Years Working with ICT (Work Experience) & & & 5.10 & 3.07 \\
\hline 1 & 62 & 16.2 & & \\
\hline $1-5$ & 70 & 18.3 & & \\
\hline $6-11$ & 113 & 29.6 & & \\
\hline $12-17$ & 47 & 12.3 & & \\
\hline $18-23$ & 40 & 10.5 & & \\
\hline $24-29$ & 32 & 8.4 & & \\
\hline 30 & 11 & 2.9 & & \\
\hline \multicolumn{5}{|l|}{ SME Annual Turnover (RM) } \\
\hline 300,000 & 14 & 32.5 & & \\
\hline $300,000-10.3$ million & 11 & 25.6 & & \\
\hline 10.4 million -20.4 million & 8 & 18.6 & & \\
\hline 20.5 million -30.5 million & 5 & 11.6 & & \\
\hline 30.6 million -40.6 million & 3 & 7.0 & & \\
\hline 50 million & 2 & 4.7 & & \\
\hline \multicolumn{5}{|l|}{ Category of SMEs } \\
\hline Small & 33 & 76.7 & & \\
\hline Medium & 10 & 23.3 & & \\
\hline \multicolumn{5}{|l|}{ Type of SME } \\
\hline Food and beverages & 17 & 39.5 & & \\
\hline Clothing and fashion & 11 & 25.6 & & \\
\hline Telecommunication services & 4 & 9.3 & & \\
\hline ICT-related & 7 & 16.3 & & \\
\hline Agribusinesses & 4 & 9.3 & & \\
\hline
\end{tabular}

Note: $F=$ frequency 
cent) were male while the remaining were female $(\mathrm{M}=1.40, \mathrm{SD}=.490)$. The average age of an employee was 31 years, five months (31.5), or 31 years approximately $(\mathrm{M}=31.05$, $\mathrm{SD}=3.09$ ). The youngest age was 18 years old while the oldest age was 50 years old. The average working experience age was five years, 10 months (5.10), or 11 years approximately. Majority (149, representing 39.0 per cent) of the respondents were aged between 18 and 28 years old. The working age of the respondents ranged from 1 to 30 years. Similarly, the experience (working) age ranged from 1 to 30 years. On average, the employees earned between ${ }^{1} \mathrm{RM}_{5}, 000$ (approximately ${ }^{2}$ USD1,127) and RM6,00o (approximately USD1,353) monthly, with majority (221, representing 57.9\%) of them earning less than $\mathrm{RM}_{3}, 000$ in a month. However, the employees' monthly income profile shows earnings ranged from $\mathrm{RM}_{3}, 000$ (approximately USD676) to RM7,00o (approximately USD1,578) (see Table 1).

\section{Development of the Research Instrument and Method of Analysis}

Seventy per cent of the questionnaire was administered face-to-face while the remaining was administered based on dropand-pick. A very high response rate of 99.3 per cent was achieved as only a few survey forms were lost during retrieval. The items used in the questionnaire were adopted with modifications from Venkatesh et al. (2003). Initially, the scale contained 57 items that sought to measure five latent constructs: performance expectancy ([PE], $\mathrm{M}=4.14$, SD $=.035$ ), effort expectancy ([EE], $\mathrm{M}=3.49$, $\mathrm{SD}=.997)$, social influence $([\mathrm{SI}], \mathrm{M}=4.12$, $\mathrm{SD}=.870$ ), facilitating conditions ( $[\mathrm{FC}], \mathrm{M}=$ 4.07, $\mathrm{SD}=.039)$ and ICT-related innovations adoption ([ICTRIA], $\mathrm{M}=3.95, \mathrm{SD}=.054$ ).

Structural equation modelling (SEM) was employed to make further analysis of the data of this study (see Comrey and Lee, 1992). At confirmatory factor analysis (CFA) the items were reduced to 25 . Five-point Likert scale which ranges from (1) strongly disagree to (5) strongly agree was employed throughout the instrument except in a few cases at the respondents' demographic information section where a mixture of openended and closed-ended questions were used. All the items used to measure each of the constructs were valid and reliable having scored as high internal consistency reliability coefficients ranging from .951 to .760 (see Table 2).

Table 2: Descriptive Attributes of the Constructs

\begin{tabular}{llllll}
\hline Construct & $\begin{array}{l}\text { Initial } \\
\text { Items }\end{array}$ & $\begin{array}{l}\text { Final } \\
\text { Items }\end{array}$ & $\begin{array}{l}\text { ICR }(\geq \\
\text { 0.7) }\end{array}$ & Mean & SD \\
\hline ICTRIA & 17 & 9 & .907 & 3.95 & .054 \\
PE & 10 & 4 & .760 & 4.14 & .035 \\
EE & 10 & 4 & .799 & 3.49 & .997 \\
SI & 10 & 4 & .890 & 4.12 & .870 \\
FC & 10 & 4 & .831 & 3.85 & .040 \\
\hline
\end{tabular}

Note: ICTRIA = ICT-related innovation adoption; ICR= Internal consistency reliability; $P E=$ Performance expectancy; EE = Effort expectancy; $S D=$ Standard deviation; $S I=$ Social influence; $F C=$ Facilitating conditions

\section{Moderating Influence of Gender, Age and Experience on the Straight Paths}

In the UTAUT model gender was theorised to moderate the relationship between PE, EE, SI and FC and technology innovations adoption.

Initially, the moderating influence of gender on the overall structural model was determined (see Hair, Black, Babin, Anderson \& Tatham, 2010; Kenny 2014). The outcome indicates that the difference between the two gender groups was significant at .05 level. The variant group was discovered to be better than the invariant group $(145.99)=(1821.111-$ 1675.121), with a value of degree of freedom (df) $70=(140-70)$ and a significance value $p=$.ooo. These results confirm the presence of moderating influence of gender on the overall model.

In the original UTAUT model, Venkatesh et al. (2003) theorised age to moderate PE, EE, SI and FC. The respondents of the study were divided into two age categories. The first category comprised SME employees with ages ranging from 18 years old to 34 years old, and were referred as 'youth'. The other category 
comprises employees with age ranging from 35 to 50 years old, and were referred to as 'elders'. When the necessary statistical tests were to determine the moderating influence of age on the overall structural model were ran (see Hair et al., 2010; Kenny, 2014), the outcome indicates that the difference between the two age groups was significant at .05 level. The variant group was discovered to be better than the invariant group $(189.711)=$ $(1604.132$ - 1414.421), with a value of degree of freedom $(\mathrm{df}) 90=(180-90)$ and a significance value $p=$.ooo. These outcomes of the analysis confirm the presence of moderating influence of age on the overall model.

Experience was theorised to moderate three direct determinants of ICT-related innovations adoption, namely performance expectancy (PE), effort expectancy (EE) and social influence (SI) as formulated in the original UTAUT model. However, in this study experience was modified and hypothesised to moderate the direct paths between each of the four key determinants and technology innovations adoption. The respondents' experience in SME was measured based on the number of years an individual employee spent in the industry. In this study, the number of working years was categorised into two groups, namely (i) the low experience group (from 1 to 15 years work experience), and (ii) the high experience group (those who worked from 16 to 30 years).

A test was performed on the overall model to determine the presence of any traces of moderating influence of experience, the result affirmatively confirmed the presence of moderation influence of experience on the model. The difference between the two gender groups was significant at .05 level. The variant group was discovered to be better than the invariant group $(155.255)=(1651.022$ - 1495.767), with a value of degree of freedom (df) $80=(795-715)$ and a significance value $p=.000$.

\section{RESULTS \\ Analysis of the Links between the Variables on the Straight Paths}

The results in Table 3 indicate performance expectancy (PE) significantly contributed toward the prediction of ICTrelated innovations adoption as shown by the following indices: $\mathrm{CR}=4.387, p=.000$, Beta $=.795$. The high value of the standardised regression weight () (.323) and a naught $p$ value (.ooo) indicate the relationship was very significant. Therefore, $\mathrm{H}^{1}$ was accepted. Effort expectancy (EE) also significantly contributed toward the prediction of ICTrelated innovations adoption as indicated by the following indices: $\mathrm{CR}=2.551, p=.005$, Beta $=.690$. The standardised regression weight value $(=.136)$ is moderately good and a $p$ value (.005), which is significant at .05 level. The significance of the construct was a bit less than that of PE. Hence, $\mathrm{H}^{2}$ was accepted. Social influence (SC) significantly contributed toward the prediction of ICTrelated innovations adoption as indicated by the following indices: a high $C R$ value (3.478), Beta $=.814$, and a corresponding high regression weight (.311) with a strongly significant p-value (.oo1), which is significant at .05 level. Therefore, $\mathrm{H}^{3}$ was accepted.

Table 3 Regression weights in the Direct Hypothesised Model

\begin{tabular}{lllllll}
\hline Hypothesis & $\begin{array}{l}\text { Hypothesised } \\
\text { Relationships }\end{array}$ & $\begin{array}{l}\text { Unstandardised } \\
\text { Regression } \\
\text { Weights (B) }\end{array}$ & SE & $\begin{array}{l}\text { Standardised } \\
\text { Regression } \\
\text { Weights }(\end{array}$ & CR & $p$-value \\
\hline $\mathbf{H}^{1}$ & PE $\Rightarrow$ ICTRIA & .795 & .181 & .323 & 4.387 & \\
$\mathbf{H}^{2}$ & EE $\Rightarrow$ ICTRIA & .690 & .267 & .136 & 2.551 & .005 \\
$\mathbf{H}^{3}$ & SI $\Rightarrow$ ICTRIA & .814 & .198 & .311 & 3.478 & .001 \\
$\mathbf{H}^{4}$ & FC $\Rightarrow$ ICTRIA & -.756 & -.135 & -.194 & -3.158 & .001 \\
\hline
\end{tabular}

Note: Correlation coefficient $\left(\mathrm{R}^{2}\right)=0.31(31 \%)$; ICTRIA = ICT-related innovations adoption; $\mathrm{SI}=$ Social influence; FC = Facilitating conditions; EE = Effort expectancy; PE = Performance expectancy; ICTRIA = ICT-related innovations adoption; $\mathrm{SE}=\mathrm{Standard}$ error; $\mathrm{CR}=$ Critical ratio; $\mathrm{p}$ = Significance value 
Facilitating conditions (FC) also contributed significantly but negatively toward the prediction of ICT-related innovations adoption. The standardised path coefficients $(=-.195, \mathrm{CR}=-3.158, p=.001)$ indicate that the data was reliable with the hypothesis testing the effect of the construct on technology innovations adoption. Thus, $\mathrm{H}^{4}$ was accepted.

Generally, the model, consisting of the four latent constructs PE, EE, SI and FC has explained $31 \%$ of the variances in technology innovations adoption by SME employees.

\section{Analysis of Gender, Age and Experience Moderation Dimensions}

Results of the test of moderating influence of gender on the individual relationship paths indicate that gender significantly moderates the effect of PE and SI on technology innovations adoption. Thus, gender dimension in $\mathrm{H}^{7}, \mathrm{H}^{9} \mathrm{H}^{11}$ and $\mathrm{H}^{12}$ was accepted. However, the influence of gender was not significant on EE and FC paths. Therefore, gender dimension in $\mathrm{H}^{8}$ and $\mathrm{H}^{10}$ was rejected. Furthermore, on the PE $\rightarrow$ ICTRIA path the influence was surprisingly significant for female workers only. Similarly, on the SI $\rightarrow$

Table 4:

Results of tests of moderating influence of gender, age and experience on the hypothesised paths

\begin{tabular}{|c|c|c|c|c|}
\hline Hypothesis & Hypothesised Path & $\begin{array}{l}\text { Unstandardised } \\
\text { Estimate (B) }\end{array}$ & $\begin{array}{l}\text { Standardised } \\
\text { Estimate 0) }\end{array}$ & $p .05$ \\
\hline \multirow[t]{7}{*}{$\mathrm{H}^{7}$} & PE $\Rightarrow$ ICTRIA & & & \\
\hline & 仓 Gender [M] & .286 & .096 & .061 \\
\hline & {$[\mathrm{F}]$} & 1.966 & .727 & \\
\hline & Age $[\mathrm{Y}]$ & 3.392 & .380 & .011 \\
\hline & {$[\mathrm{E}]$} & 1.074 & .841 & \\
\hline & Experience $[\mathrm{H}]$ & 1.074 & .841 & \\
\hline & {$[\mathrm{L}]$} & 3.392 & .280 & .842 \\
\hline \multirow[t]{7}{*}{$\mathrm{H}^{8}$} & $\mathrm{EE} \Rightarrow$ ICTRIA & & & \\
\hline & 仓 Gender [M] & .192 & .069 & .067 \\
\hline & {$[\mathrm{F}]$} & .001 & .001 & 990 \\
\hline & Age [E] & .007 & .005 & .025 \\
\hline & {$[\mathrm{Y}]$} & .445 & .822 & .821 \\
\hline & Experience $[\mathrm{H}]$ & .007 & .005 & .922 \\
\hline & {$[\mathrm{L}]$} & .445 & .822 & .821 \\
\hline \multirow[t]{7}{*}{$\mathrm{H}^{9}$} & SI $\Rightarrow$ ICTRIA & & & \\
\hline & 仑े Gender $[\mathrm{M}]$ & .277 & .489 & .066 \\
\hline & {$[\mathrm{F}]$} & .378 & .415 & \\
\hline & Age $[Y]$ & -.777 & .324 & .031 \\
\hline & {$[E]$} & .570 & .644 & .563 \\
\hline & Experience $[\mathrm{H}]$ & .046 & -.059 & .762 \\
\hline & {$[\mathrm{L}]$} & .004 & .007 & \\
\hline \multirow[t]{7}{*}{$\mathrm{H}^{10}$} & $\mathrm{FC} \Rightarrow$ ICTRIA & & & \\
\hline & 仓 Gender [M] & -.367 & -.178 & .167 \\
\hline & {$[\mathrm{F}]$} & .271 & .151 & .004 \\
\hline & Age $[\mathrm{Y}]$ & -.966 & -1.124 & -.581 \\
\hline & {$[\mathrm{E}]$} & .550 & .344 & .003 \\
\hline & Experience $[\mathrm{H}]$ & .699 & 1.114 & .890 \\
\hline & {$[\mathrm{L}]$} & .550 & .344 & .036 \\
\hline
\end{tabular}

Notes: ICTRIA = ICT-related innovations adoption; PE= Performance expectancy; EE= Effort expectancy; FC= Facilitating conditions; $\mathrm{SI}=$ Social influence; E= Elder ( 35 to 50 years old); $\mathrm{Y}=$ Youth (18 to 34 years old); M= Male; F= Female; H= High (16 to 30 years); L= Low (1 to 15 years) 
ICTRIA path the influence was significant for female workers only as shown in Table 4.

Age significantly moderates the relationship between PE, EE, SI, FC and technology innovations adoption. Because of this, age dimension in $\mathrm{H}^{7}, \mathrm{H}^{8}, \mathrm{H}^{9}$ and $\mathrm{H}^{10}$ was accepted. In addition, on the PE $\rightarrow$ ICTRIA path the effect was significant for both older and younger employees, with the effect being stronger for the elders. On the EE $\rightarrow$ ICTRIA path the effect was also significant for older employees. Similarly, the effect was significant for older employees on the $\mathrm{FC} \rightarrow$ ICTRIA path. However, influence was surprisingly significant for younger female workers on the SI $\rightarrow$ ICTRIA (refer to Table 4 ).

Results for the moderating influence of experience on the effect of PE, EE, SI and FC on technology innovations adoption shows that experience significantly moderates the paths between PE, SI, FC and ICTRIA only. Hence, the experience dimension in $\mathrm{H}^{7}, \mathrm{H}^{9}$ and $\mathrm{H}^{10}$ was accepted. While, the moderating influence of experience on EE path was not found to be important, indicating that experience dimension in $\mathrm{H}^{8}$ was rejected. Interestingly however, the moderating effect of experience on all the paths $(\mathrm{PE} \rightarrow$ ICTRIA, $\mathrm{SI} \rightarrow$ ICTRIA and $\mathrm{FC} \rightarrow$ ICTRIA) was important only at the high level. Whereas, the influence of experience on SI $\rightarrow$ ICTRIA and $\mathrm{FC} \rightarrow$ ICTRIA paths was only significant at the low experience level on both paths. Generally, the influence of the workers' high experience was strongest on all the paths except for the $\mathrm{EE} \rightarrow$ ICTRIA and $\mathrm{FC} \rightarrow$ ICTRIA paths (refer to Table 4 ).

\section{Discussion}

\section{Relationships between PE, EE, SI, FC and ICTRIA}

Although not the focus of this paper, to determine the moderating influence of the human resource demographic attributes under investigation on the paths between the four predictors (PE, EE, SI and FC) and technology innovations adoption requires that the association between the four constructs be determined first (see Hair et al., 2010). This study found that all the four mentioned latent constructs predict technology innovations adoption by SMEs at various degrees of significance. Performance expectancy has been very strongly and positively significant, suggesting that the adoption and adoption of technology innovations by SME employees in job is tremendously affected by the cost-benefit judgment.

Thenext mostsalientconstructsaresocial influence (SI) and facilitating conditions (FC). Both the SI and FC's significance suggests that despite the salience of expected value judgment (with the significance of PE), employees would consider social implications of technology innovations adoption and access to stand-by technical support with the use of systems in the job in case of unforeseen hitches. Theoretically, these two attributes are often associate with female workers, new users, young users and the workers. Furthermore, the significance of effort expectancy (EE) adds to the implication already established that most of workers of firms would consider access to any form of technical help and support handy when using a technology. Because, the core concepts of EE have roots in the ease associated with a system use in job, an attribute that is also theoretically often linked to female human resource persons. This suggests that most of the human resource persons in SMEs would need some form of use skills training, for example; especially start-ups. The notions of these findings are grounded in the works of Bandura (2001) and Venkatesh et al. (2003).

When SME managers adopt ICT-related innovations for business growth, in addition to the factors mentioned and discussed above they would consider the technology use skills, experience, creativity and managerial attributes of the employees they would want to hire to run their business. This can be well understood if the links between qualitative management and job performance output is regarded (Goswami, \& Dutta, 2017; Venkatesh et al., 2003). 


\section{Moderating Influence of Gender}

This moderating influence of demographics (gender, age and experience) on technology innovations adoption and use by SME employees was investigated and the findings revealed that gender significantly moderates the relationship between performance expectancy (PE), social influence (SI) and technology innovations adoption. The influence was very strong and positive on all the four constructs. However, the influence was salient on female workers only on the PE and SI relationship paths. The salience of the regulation influence of gender on the PE effect has been a novel, unexpected finding though.

Past research has consistently reported the influence of gender on PE to be important on (young) male workers (see Venkatesh et al., 2012; Venkatesh et al., 2003; Zarehmohzzabieh et al., 2014). However, such a novel finding is not peculiar to the present study since it has been supported by many past studies in non-Malaysian context such as Al-Qeisi (2009) and Carlsson et al. (2006). This study was performed in a Southeast Asian country, Malaysia, where gender disparity in entrepreneurship technology innovations use is conspicuously present (Razak, Aziz, Hashim, Amir, \& Zulkifli, 2010) despite developments recorded in recent decades in attempts to close gender gaps and empower women (Goy, Wong, Low, Mohd Noor, Fazli-Khalaf, Onyeneho, Daniel, Azizan, Hasbullah, \& Uzoigwe, 2017; Selamat, Endut, Karupaiah, Isa, Fernando, \& Zahari, 2016; UNDP, 2016); for example, it is reported that 63 per cent of Malaysian women gain access to education and that 50 per cent of them are actively involved in various entrepreneurial endeavours (UNDP, 2016).

This finding further suggests that firm managers would consider assigning some ICT-related roles to women employees more than they would to men workers, or at least would not give preference to male employees. However, to continue tapping the skills of the male workers, managers should consider employing the male workers' management creativity and innovativeness to diversify the firm's product brands, manage human and capital resources to improve and sustain the firm's competitive advantages in the market (see Li \& Kishore, 2006).

The present study also discovered that gender was non-significant at moderating the effect of effort expectancy on technology innovations adoption, suggesting that either majority of the respondents had high technology use skills and experience or their responses to questions on effort expectancy were largely biased. However, female gender played a significant moderating role on the effect of social influence and technology innovations adoption. This finding agrees with many previous studies such as Venkatesh et al. (2003), Zarehmohzzabieh et al. (2014) and Goswami and Dutta (2017).

Similarly, female gender has been found to significantly moderate the relationship between facilitating conditions and technology innovations adoption. This finding supports past research that expectancies bordering facilitating conditions are salient on women workers, particularly aged women (Venkatesh et al., 2003). The finding further highlights the need for SME managers to consider providing access to technical infrastructure/facility to their employees, particularly women works in the organisation. For enhanced performance, improved productivity and bumper output, conducive work atmosphere that guarantees an effective technology use on the job should be prioritised.

\section{Moderating Influence of Age}

Age was found to have significantly influenced the effect of performance expectancy (PE), effortexpectancy (EE), social influence (SI) and facilitating conditions (FC) on technology innovations adoption. Age was computed as a continuous variable (Hair et al., 2010), and it was divided into two groups, namely elders ( 35 to 50 years old) and youth (18 to 34 years old). This study found that both older and younger ages significantly regulated the influence of performance 
expectancy and technology innovations adoption, with the effect being stronger on the older workers. Usually younger workers would be more likely to be associated with job performance output quality (Venkatesh et al., 2003). However, since in this study performance expectancy was hypothesised to be influenced by experience (details in due course), and experience is often associated with advancing age (Zarehmohzzabieh et al., 2014), therefore it is not surprising that the workers' advanced age has been discovered to influence the effect of performance expectancy on the initiation or continuation of technology innovations adoption in the firm for entrepreneurial development.

Given that effort expectancy (EE) is associated with the degree of taskintensiveness at using a system and, older women workers have been found to be predisposed to carry out task-intensive jobs (Venkatesh et al., 2003); therefore, it is not surprising that only older age was significant in moderating the effect of EE on technology innovations adoption. Additionally, this study found that advanced age significantly regulates the effect of social influence on technology innovations adoption. The literature supports this finding in that affiliation and reliance on support at work are consistently associated with old age (Higón, 2012; Venkatesh et al., 2003). However, since older workers have been found to have a high propensity to yield high output performance, managers should consider reinforcing older employees with the necessary system support and then assigning task-oriented jobs to them, e.g., data analysis, data retrieval and product labeling and packaging.

Thesalience of youngerage on the SI effect was unexpected like the influence of female gender on the PE effect. The importance of younger female employees in SI implies that either most of the younger female workers were newly-hired and unskilled or the social influence here could have referred to peer (age group) influence rather than disposition to seek help or support with the use of a system in the job because, constructs related to social influence have been consistently significant for older workers (see Venkatesh et al., 2003). These two novel findings have very important implications for future research.

\section{Moderating Influence of Experience}

Experience has been found to significantly control the influence of performance expectancy (PE), social influence (SI) and facilitating conditions (FC) and technology innovations adoption. The influence of the SME workers' experience on the effect of only one of the four predictors, namely $\mathrm{PE}$ on the relationship paths with technology innovations adoption was salient at the high (experience) level while its moderating influence on social influence (SI) and facilitating conditions (FC) was salient at low (experience) level only. However, the influence of experience on the effect of effort expectancy was nonsignificant. Some of These finding have supported previous research while the others have not. The salience of low experience on the effect of social influence and facilitating conditions supports past literature that expectancies associated with social influence and facilitating conditions (which often associated with advanced with older workers, especially women) wanes off with increasing experience (Venkatesh et al., 2003; Venkatesh et al., 2012). These findings suggest that SME managers should consistently prioritise recruiting high experienced, skillful and knowledgeable workers especially at key units of the firm to run technology-applied jobs in the firm.

The moderating influence of experience on the effect of expectancies associated with organisational expansion and diversification was non-significant. This finding suggests that the physical, fiscal and labor force expansion of the firm would chiefly depend on the performance output quality, technology use knowledge and skills and management creativity and innovative characteristics rather than experience. Additionally, those characteristics are usually associated with younger managers and employees (Rahman \& Ramos 2014; Venkatesh et al., 2003), hence SME managers/owners should capitalise on 
those qualities when considering opening business branches, increasing the size of their labor force, or sourcing loans to augment the capital base of the enterprise. Then, managers may consider tapping the vast experience of their employees to develop strategies for sustaining technology innovations adoption in the now-newly expanded organisation for further business growth and success.

This finding also suggests that with high working experience, SMEs' workers would be more likely to change their behaviour in the adoption and use of technology innovations in business; they would be able to make informed and more favourable decisions regarding technology adoption and use. However, experience did not regulate the influence of effort expectancy on technology innovations use, suggesting a somewhat moderate technology use experience level among the respondents. This finding supports Venkatesh et al. (2003), Dholakia and Kshetri (2004) and Higón (2012).

\section{CONCLUSION}

Findings from the regression analysis indicate that performance expectancy and social influence, significantly predict technology innovations use by the employees and managers of SMEs. The conceptual model predicted 31 per cent of variances associated with technology innovations adoption. Similarly, effort expectancy and facilitating conditions are recommended for further investigation. Additionally, gender, age and experience variously moderate the effect of the four predictors on technology innovations adoption. Only female gender has been found to be salient on performance expectancy and social influence, and only younger age of workers is salient for the latter. Performance expectancy is theorised to be salient on male workers (see Venkatesh et al., 2003), has been contrarily found to be salient on female workers, without age difference though; social influence which is theorised to be important for older workers is found to be salient for younger employees.

These novel findings suggest that female employees do perform task-oriented jobs in the organisation and new, less experienced young recruits could be disposed to reliance on the help of others for heavier tasks (see Venkatesh et al., 2003; Zarehmohzzabieh et al., 2014). These findings suggest a paradigm shift from a male-dominated industrial technology adoption context to a femaledominatedone, ornear-equilibriumsituation, at least in a non-Western (Malaysian) context. furthermore, these findings highlight the real-world situation in Malaysia where, in the recent decades, women are increasingly embracing entrepreneurships and joining workforce by not less than 50 per cent of their quota according recent statistics (see UNDP, 2016). However, only advanced age has been found to be significant on effort expectancy and facilitating conditions, while only young age is significant for social expectancy. Experience, which is often associated with advanced age (Venkatesh et al., 2003), did not moderate the effect of effort expectancy. These results have some implications for practitioners, policymakers and researchers as follows.

1. Expected benefits in the adoption and use of ICT-related innovations can change SME workers' behaviour. Hence, SMEs would adopt new technologies and innovations in business only when the expected benefits outweigh the effort and technical skills required for use. Constrained by limited resources, SMEs mustallocate their time, effort and limited resources to cost-effective entrepreneurial matters. Hence, they would not prioritise technology innovations adoption unless it offers real gains.

2. Female employees, especially elder women (aged from 36-50 years old) would be taking up performance-laden tasks related to technology use in the firm, and they can be considered as a perfect replacement for male workers, or at least, as a matching complement/substitute to them.

3. Newly-hired, young less-experienced workers are more liable to exhibit tendencies especially at younger ages to 
seek support from others in the job.

\section{Limitations}

A key imitation of this study is that it was conducted in a Malaysian state of Selangor only. Even though that state was selected because most Malaysian SMEs are located there (Abd Rahman et al., 2013), the context can influence the findings. Hence, caution should be exercised when interpreting these findings, especially in Western contexts. Furthermore, this study focused on the employees of Malaysian SMEs only (as opposed to consumers, for example). Furthermore, this study focused on ICTrelated innovations generally without any specification. Hence, future research should focus on specific SMEs e.g., agribusinesses, food and beverages, metal works, etc. and specific ICT-related innovations, e.g., cloud computing, data mining, the use of websites, the use of Internet, the use of instant messaging applications, the use of social networking sites and the use of e-commerce. Finally, given that SME workers' perceptions may change over time, especially when they get more and more working experience (Venkatesh \& Davis, 200o; Zarehmohzzabieh et al., 2014), future research should consider embarking on a longitudinal study.
Abd Rahman, A., Kamarulzaman, N.H., \& Sambasivan, M. (2013). A study on organisational culture, performance, and technological adoption behaviours of Malaysian food-processing SMEs. Pertanika Journal of Social Sciences $\mathcal{E}$ Humanities, 21 (Spec. ed. June), 231-256.

Abdullah, N.H., Shamsuddin, A., Wahab, E., \& Hamid, N.A. (2012). Preliminary qualitative findings on technology adoption of Malaysian SMEs. In Humanities, Science and Engineering (CHUSER), 2012 IEEE Colloquium on (pp. 15-20), December 3-4, Kota Kinabalu, Sabah, Malaysia.

Agarwal, R., \& Prasad, J. (1999). Are individual differences germane to the acceptance of new information technologies? Decision sciences, 30 (2): 361-391.

Al-Gahtani, S.S., Hubona, G.S., \& Wang, J. (2007). Information technology (IT) in Saudi Arabia: Culture and the acceptance and use of IT. Information E Management, 44(8): 681-691.

AlRahbi, H.S.A. (2017). 'Factors influencing social media adoption in small and medium enterprises (SMEs).' Doctoral dissertation, Department of Computer Science, Brunel University London, UK. Retrieved from http://bura. brunel.ac.uk/bitstream/2438/14514/1/ FulltextThesis.pdf\%20 on 2 June 2017.

Aoun, C., Vatanasakdakul, S., \& Li, Y. (2010, December). AIS in Australia: UTAUT application \& cultural implication. In 21st Australasian Conference on Information Systems (ACIS 2010), (paper 17, pp. 1-12), Brisbane, Australia. AIS.

Bandura, A. (2001). Social cognitive theory of mass communication. Media Psychology, 3(3): 265-299. 
Cheng, D., Liu, G., Qian, C. \& Song, Y-F. (2008). Adoption of Internet banking: An integrated model. Proceeds of the 4th International Conference on Wireless Communications, Networking and Mobile Computing (WiCOM'o8), (pp. 1-4), EEE.

Chiu, C.Y., Chen, S., \& Chen, C.L. (2017). An integrated perspective of TOE framework and innovation diffusion in broadband mobile applications adoption by enterprises. International Journal of Management, Economics and Social Sciences (IJMESS), 6(1): 14-39.

Comrey, A.L., \& Lee, H.B. (2013). A first course in factor analysis ( $2^{\text {nd }}$ ed.). New York: Psychology Press.

Dholakia, R.R., \& Kshetri, N. (2004). Factors impacting the adoption of the Internet among SMEs. Small Business Economics, 23 (4): 311-322.

DOSM (2014). SMEs Census 2011. Retrieved from www.statistics.my.gov/ on 25 May 2014.

Duan, Y., Mullins, R., Hamblin, D., Stanek, S., Sroka, H., Machado, V., \& Joao Araujo, A. (2002). Addressing ICTs skill challenges in SMEs: Insights from three country investigations. Journal of European Industrial Training, 26 (9): 430-441.

Ghobakhloo, N.B. Zulkifli, F.A., \& Aziz (2010). The interactive model of user information technology acceptance and satisfaction in small and mediumsized enterprises. European Journal of Economics, Finance and Administrative Sciences, 19 (1): 7-27.

Escobar-Rodríguez, T., \& Carvajal-Trujillo, E. (2014). Online purchasing tickets for low cost carriers: An application of the unified theory of acceptance and use of technology (UTAUT) model," Tourism Management, 43: 70-88.

Goswami, A., \& Dutta, S. (2017). E-Commerce adoption by women entrepreneurs in India: An application of the UTAUT model, Business and Economic Research, 6 (2): 440-454.

Goy, S.C., Wong, Y.L., Low, W.Y., Noor, S.N.M., Fazli-Khalaf, Z., Onyeneho, N., Daniel, E., Azizan, S., Hasbullah, M., \& GinikaUzoigwe, A. (2017). Swimming against the tide in STEM education and gender equality: A problem of recruitment or retention in Malaysia. Studies in Higher Education, 1-17, DOI: 10.1080/03075079.2016.1277383

Hashim,J.(2015).Informationcommunication technology (ICT) adoption among SME owners in Malaysia. International Journal of Business and Information, 2 (2): 221-240.

Hair, J.F., Anderson, R.E., Babin, B.J., \& Black, W.C. (2010). Multivariate data analysis: A global perspective (vol. 7), New Jersey, Upper Saddle River: Pearson.

He, D., \& Lu, Y. (2007). Consumers' perceptions and acceptances towards mobile advertising: An empirical study in China. In Proceedings of International Conference on Wireless Communications, Networking and Mobile Computing (WiComzoo7) (pp. 3775-3778), IEEE.

Higón, D.A. (2012). The impact of ICT on innovation activities: Evidence for UK SMEs. International Small Business Journal, 30 (6): 684-699.

Kenny, D.A. (2014), Measuring model fit. Retrieved from http://davidakenny. net/cm/fit.htm\#RMSEA on 28 August 2015 .

Kogilah, N., Santhapparaj, A. S., \& Eze, U. C. (2008). An empirical study of website adoption among small and medium enterprises in Malaysia. Proceedings of the 1oth International Business Information Management Association (IBIMA) Conference on Innovation and Knowledge Management in Business Globalisation, Kuala Lumpur, Malaysia, pp. 339-51.

Li, J.P., \& Kishore, R. (2006). How robust is 
the UTAUT instrument? A multigroup invariance analysis in the context of acceptanceand use of online community weblog systems. In Proceedings of the 2006 ACM SIGMIS CPR Conference on Computer Personnel Research: Fortyfour years of Computer Personnel Research: Achievements, Challenges and the Future (pp. 183-189), ACM.

Maldonado, U.P.T., Khan, G.F., Moon, J. \& Rho, J.J. (2011). E-learning motivation, students' acceptance/use of educational portal in developing countries. Online Information Review, 35(1): 66-85.

Maruping, L.M., Bala, H., Venkatesh, V., \& Brown, S.A. (2017). Going beyond intention: Integrating behavioural expectation into the unified theory of acceptance and use of technology. JournaloftheAssociationforInformation Science and Technology, 68(3): 623-637.

MCMC (2014). Communications and multimedia pocket book of statistics, 2013, (Q4). Malaysian Multimedia Communications and Multimedia Commission (MCMC), retrieved from http://www.skmm.gov.my/ skmmgovmy/media/General/pdf/ SKMM_Q3_ENG.pdf on 29 January 2014.

Mehta, A. (2016). The relationship between rural retailing, women agropreneurs innovativeness and firm performance: a conceptual review and avenues for future research. International Journal of Green Economics, 10 (2): 151-190.

Morris, M.G., \& Venkatesh, V. (200o). Age differences in technology adoption decisions: Implications for a changing work force. Personnel Psychology, 53 (2): 375-403.

Morris, M.G., Venkatesh, V., \& Ackerman, P.L. (2005). Gender and age differences in employee decisions about new technology: An extension to the theory of planned behaviour. IEEETransactions on Engineering Management, 52 (1): 6984.
Odoom, R., Anning-Dorson, T., \& Acheampong, G. (2017). Antecedents of social media usage and performance benefits in small-and mediumsized enterprises (SMEs). Journal of Enterprise Information Management, $30(3): 383-399$.

Rusdi, S.D., Hassan, R., Munir, Z.A., \& Mohamad, S.S. (2017). Information and communication technology (ICT) adoption factors and its influence on employees' performance in SMEs. Advanced Science Letters, 23(8): 7841$7844(4)$.

Qureshi, S., \& Xiong, J. (2017). Understanding the role of technology in the development of micro-enterprises: Concepts to study in making a better world. In Proceedings of the 5oth Hawaii International Conference on System Sciences (HICSS 2017) (pp. 2627-2636), 4-7 January, Hilton Waikoloa, Hawaii, USA.

Rahman, H., \& Ramos, I. (2014). Information systems for small and mediumsized enterprises. In Devos, J., van Landeghem, H., \& Deschoolmeester, D. (Eds.), Progress in IS (pp. 313-335), Berlin Heidelberg: Springer-Verlag.

Razak, N.A., Aziz, J., Hashim, F., Amir, Z., \& Zulkifli, S.H. (2010). The acculturation of ICT among rural women e-entrepreneurs. In gth WSEAS International Conference on Education and Educational Technology, EDU'io (pp. 278-283), 4-6 October, Iwate, Japan.

Salancik, G.R. \& Pfeffer, J. (1978). A social information processing approach to job attitudes and task design. Administrative Science Quarterly, 23(2): 224-253.

Selamat, N.H., Endut, N., Karupaiah, P., Isa, S.M., Fernando, Y., \& Zahari, M.M. (2016). Why patriarchal matters: Entrepreneurship performance among women entrepreneurs in Malaysia. The NIEW Journal, 8, 42-49. 
SMECORP (2017a). SME Statistics: Economic census 2016 - Profile of SMEs (Contribution of SMEs in 2016). Small and medium enterprises corporation of Malaysia (SMECORP), retrieved from http://www.smecorp.gov.my/index. php/en/policies/2015-12-21-19-09-49/ sme-statistics on 4 February 2018.

SMECORP (2017b). Appendix 4: SME definition. In SME annual report, 2016/2017, p 157. Small and medium enterprises corporation of Malaysia (SMECORP), retrieved from http:// www.smecorp.gov.my/index.php/en/ sme-annual-report-2015-16?id $=2150$ on 4 February 2018.

Srinivas, K., \& Yasmeen, M.S. (2017). A study on employee engagement in small and medium enterprises in digital economy. In Aluvala, R. (Ed.), Millennial Workforce-A Contemplation (pp.5764), Hyderabad: Zenon Academic Publishing.

Taiwo, A.D., \& Downe, A. G. (2013). The theory of user acceptance and use of technology (UTAUT): A meta-analytic review of empirical findings. Journal of Theoretical and Applied Information Technology, 49(1): 48-58.

Tan, K.S., Chong, S.C., Lin, B., \& Eze, U.C. (2010). Internet-based ICT adoption among SMEs: Demographics versus benefits, barriers and adoption intention. Journal of Enterprise Information Management, 23 (1): 27-55.

Tatoglu, E., Bayraktar, E., Golgeci, I., Koh, S.L., Demirbag, M., \& Zaim, S. (2016). How do supply chain management and information systems practices influence operational performance? Evidence from emerging country SMEs. International Journal of Logistics Research and Applications, 19 (3): 181199.

Taylor, S., \& Todd, P.A. (1995). Understanding information technology usage: A test of competing models," Information Systems Research, 6 (2): 144-176.
UNDP (2016). UNDP Human development report 2016: Human development for everyone. UNDP, UN, New York, USA. Retrieved from http://hdr.undp.org/ sites/all/themes/hdr_theme/countrynotes/MYS.pdf on 18 June 2017.

Venkatesh, V., Brown, S.A., Maruping, L.M., \& Bala, H. (2008). Predicting different conceptualisations of system use: The competing roles of behavioural intention, facilitating conditions, and behavioural expectation. MIS quarterly, 32 (3): 483-502.

Venkatesh, V., \& Davis, F.D. (2000). A theoretical extension of the technology acceptance model: Four longitudinal field studies. Management Science, 46 (2): 186-204.

Venkatesh, V., \& Morris, M.G. (2000). Why don't men ever stop to ask for directions? Gender, social influence, and their role in technology acceptance and usage behaviour. MIS Quarterly, 24 (1): 115-139.

Venkatesh, V. Morris, M.G., Davis, G.B., \& Davis, F.D. (2003). User acceptance of information technology acceptance: Toward a unified view," MIS Quarterly, 27 (3): 425-478.

Verheul, I., Thurik, R., \& Grilo, I. (2010). Explaining preferences and actual involvement in self-employment: New insights into the role of gender. ERIM Report Series Research in Management, No. ERS-2008-003-ORG. Retrieved from http://hdl.handle.net/1765/10979 on 15 June 2017.

Zarehmohzzabieh, Z., Samah, B.A., Omar, S.Z., Bolong, J., \& Shaffril, H.A.M. (2014). Fishermen's acceptance and use of information and communication technology integration in Malaysia. Exploring the moderating effect of age and experience. Journal of Applied Sciences, 14 (9): 1-10. 
INFORMASI Kajian Ilmu Komunikasi Volume 48. Nomor 1. Juni 2018

\section{(Endnotes)}

1 RM: Malaysian currency, Ringgit Malaysia

2 USD: The United States Dollar 